\title{
Crowding of dairy cows in a cubicle barn during the hot summer months
}

\author{
Miljan Erbez¹, Knut Egil Bøe ${ }^{3}$, Daniel Falta² and Gustav Chládek² \\ ${ }^{1}$ Ministry of Agriculture, Forestry and Water Management of Republic of Srpska, Banja Luka, Bosnia and Herzegovina, \\ ${ }^{2}$ Department of Animal Breeding, Faculty of Agronomy, Mendel University, Brno, Czech Republic, ${ }^{3}$ Department of \\ Animal and Aquacultural Sciences, Norwegian University of Life Sciences, Ås, Norway
}

\begin{abstract}
This study was carried out on a commercial dairy farm located in the South-Moravian region of the Czech Republic. Two video cameras (IP7330 and PZ6122, Vivotek Technology), located over cubicles below the ceiling, provided video recordings, which were taken in 15min intervals from 02.00 to 08.00 (Period 1 - morning) and from 10.00 to 19.30 (Period 2 - afternoon) one day per week (i.e. on Thursday) from 2 July (week 27) to 15 October (week 42). Air temperatures and humidity were measured every fifteen minutes during the days of behavioural observations using three $\mathrm{HOBO}$ data loggers. In order to determine the spatial distribution of dairy cows, the research barn was visually divided into three sectors of equal size: A - closest to the middle of the barn, B - between and C - the edge of the stable. Inside the barn, air temperatures predominantly ranged between $22^{\circ} \mathrm{C}$ and $30^{\circ} \mathrm{C}$ during Period 2 , while in Period 1 they were lower by $5^{\circ} \mathrm{C}$ to $11^{\circ} \mathrm{C}$. During Period 1 , dairy cows were distributed quite evenly among sectors. Since week 29 , however, the number of cows in sector A began to increase in Period 2 and did not return to the normal distribution pattern before week 42 . Interestingly, the crowding was observed only during Period 2 and not in Period 1. Crowding began to appear when average daily temperatures increased to $20^{\circ} \mathrm{C}$.
\end{abstract}

Keywords: crowding, dairy cows, behaviour, summer

\section{Introduction}

This study was carried out to examine claims of cow breeders in Southern Czech Republic which noticed crowding behaviour of cows in cubicle and loose housing barns during the warm summer period. In this period the cows were gathered in the central part of a barn without obvious reason. The observed phenomenon was described as follows: on hot days, dairy cows moved into one section of the cubicle barn and they apparently became more intense as temperatures increased. Visits to eight dairy farms situated in the South-Moravian region (and also in other parts of the Czech Republic) confirmed the same crowding phenomenon. Hurnik et al. (1995) defined it as »....an unusually high spatial density of animals which may cause discomfort to some or all animals in the group but does not result in a serious deprivation and/or injury".

According to some authors, this crowding can be caused by restricted access to some important resources such as food and water (e.g. Huzzey et al. 2006, Hill et al. 2009) or to lying 
places (e.g. Friend et al. 1979). However, crowding can also be a thermoregulatory behaviour, which enables organisms to reduce heat losses at low ambient temperatures, above all in pigs (Boon 1981, Andersen et al. 2000) but also in sheep (Bøe 1990). The studies of Tapkı \& Şahin (2006) showed that in cattle exposed to high environmental temperatures, the total time spent for eating and rumination decreased while the time for standing increased.

Erbez et al. (2010a) found that crowding of dairy cows could contribute to decrease in milk production due to less favourable environmental conditions and disturbed social relations. In the same study, they also created and applied a scale enabling them to categorise the crowding behaviour on the basis of space available for individual animals.

The aim of this study was to study the crowding behaviour of dairy cows in cubicle housing systems during the summer. In this study our hypothesis was that dairy cows should be evenly distributed in all parts of the barn during the day.

\section{Material and methods}

This study was carried out on a commercial dairy farm located in the South-Moravian region of the Czech Republic, namely in the village of Říčany ( $\left.49^{\circ} 12^{\prime} 32.12^{\prime \prime}, 16^{\circ} 23^{\prime} 43.05^{\prime \prime}\right)$ at the altitude of $351 \mathrm{~m}$. The experiment started on 2 July (week 27) and ended on 15 October (week 42).

\section{Housing}

Dairy cows were housed in a three-year-old naturally ventilated cubicle barn with open side walls. Cows were separated into four equal pens with approximately 100 cubicles in each of them. Total available space in the research pen was $628.28 \mathrm{~m}^{2}$ (i.e. alleys + cubicles) (Figure 1). There were 64 head to head cubicles +1 headed to a water trough, and 38 cubicles situated on one side of the barn, all with open front lunge space. There were around 1.1 cubicles per cow. The cubicles were approximately $1.2 \mathrm{~m}$ wide, $2.5 \mathrm{~m}$ long and $1.25-1.3 \mathrm{~m}$ high (the height of the neck rail from bedding surface). As bedding, pressed and dried liquid manure was used in cubicles and in alleys there was a concrete slatted floor. The feeding barrier provided approximately $0.46 \mathrm{~m}$ of feeding space per cow. Water troughs were located on both ends and in the middle of the research pen (Figure 1). The pen was oriented to the south-east. Dimensions presented in this figure are in centimetres.

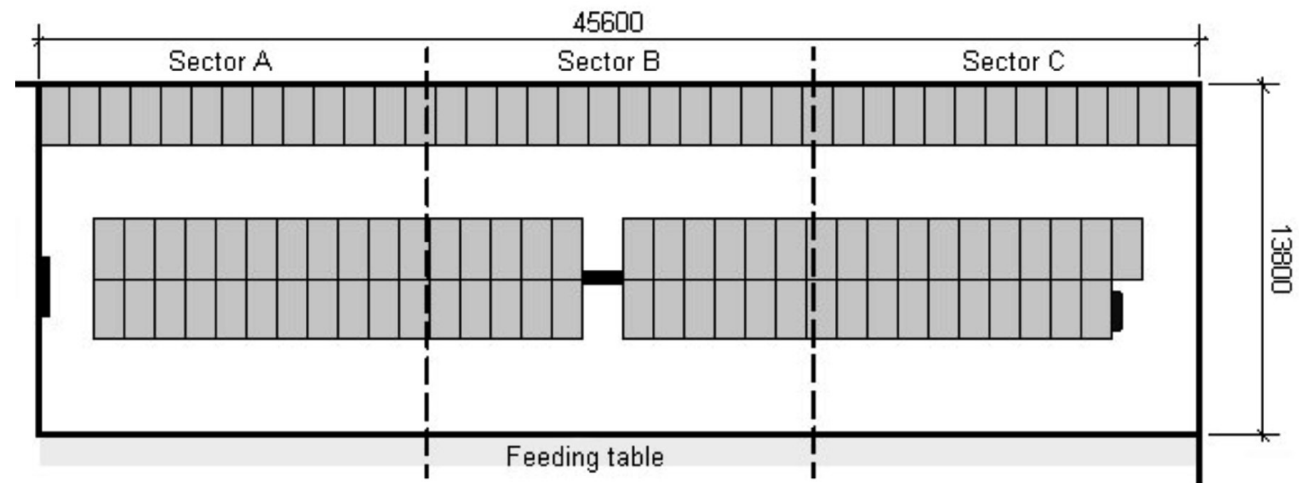

Figure 1

The lay-out of the experimental section of the barn 


\section{Animals and feeding}

All dairy cows observed in this study were of the dual purpose Czech Fleckvieh breed of cattle (Hanuš et al. 2011). All animals were dehorned. Cows were on the 2 nd to the 7 th lactation but approximately $85 \%$ of all were on the 2 nd to the 4 th lactation. The number of cows kept in research section of the barn ranged from 98-101. The cows were milked two times per day (viz. from 08.00 to 10.00 and from 19.30 to 21.00) in an adjacent milking parlour. They received ca $9 \mathrm{~kg}$ of DM in form of a total mixed ration (TMR ) two times a day (approximately at 04.30 and 16.00).

\section{Behavioural observations}

In order to determine the spatial distribution of dairy cows, the research pen was visually divided into three sectors of equal size (A, B and C, see Figure 1). The area of each sector was approximately $209 \mathrm{~m}^{2}$. Two video cameras (IP7330 and PZ6122, Vivotek Technology, New Taipei City, Taiwan), located over cubicles below the ceiling (Figure 1), provided video recordings, which were taken in 15-min intervals from 02.00 to 08.00 (Period 1 - morning) and from 10.00 to 19.30 (Period 2 - afternoon) always one day per week (i.e. on Thursday) from 2 July (week 27) to 15 October (week 42). Cameras were placed about $7 \mathrm{~m}$ above the stall floor. Due to other aims of research two observation days had to be removed (week 31 and week 34). Hence the final dataset have included 14 observation days.

Numbers of dairy cows present in each sector ( $A, B$ and $C$ ) were scored according to the video images. Observation on animal behaviour was made through 4 characteristics that we focused on: feeding (overhead feeding table), standing in alleys, lying in cubicles and standing in cubicles (with at least two legs in the cubicle).

\section{Climatic conditions}

In order to quantify the heat load that the cows were exposed to inside the building, air temperature and air humidity were measured every fifteen minutes on the days of behavioural observations. For this monitoring, three HOBO data loggers were used (H08-007-02, Onset Computer Corporation, Bourne, MA, USA). Loggers were located approximately $1.40 \mathrm{~m}$ above the floor at three different locations inside the barn. Using the recorded data, the mean air temperatures in Period 1 (02.00-08.00 morning) and Period 2 (10.00-19.30 afternoon) were calculated for each of the observation days. A temperature-humidity index (THI) was also calculated using the formula:

$$
T H I=0.72(W+D)+40.6
$$

where $W$ is the wet bulb, $D$ is the dry bulb temperature (in ${ }^{\circ} \mathrm{C}$ ).

\section{Statistical analysis}

Correlations existing between ambient air temperatures in the room (mean for the afternoon Period) and numbers of dairy cows present in sector $A$ in the afternoon, as well as correlations between crowding (\% of cows in sector $\mathrm{A}$ ) and numbers of cows standing or feeding, were calculated using Pearson's formula. 


\section{Results}

\section{Climatic conditions}

Inside the building, air temperatures ranged mostly between $22^{\circ} \mathrm{C}$ and $30^{\circ} \mathrm{C}$ during the Period 2 (afternoon), while in Period 1 (morning) they were lower by $5^{\circ} \mathrm{C}$ to $11^{\circ} \mathrm{C}$ (Figure 2). After week 38, air temperatures decreased and the heat load imposed on dairy cows was reduced. Until week 38, THI values were generally higher than 70 in Period 2 on all observation days.
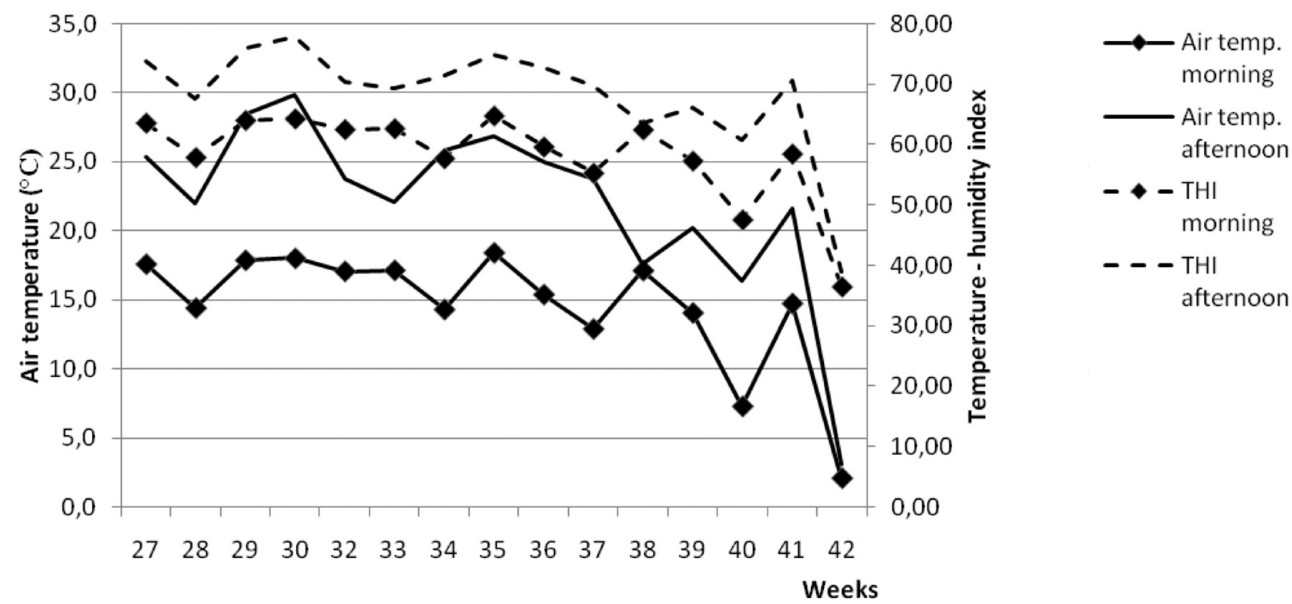

Figure 2

Air temperature and THI-index in Periods 1 (morning) and 2 (afternoon)

\section{Crowding behaviour}

During Period 1, cows were distributed quite evenly among sectors A, B and C (Figure 1). In the course of Period 2, the number of cows in sector A began to increase in week 29 and did not return to the normal level before week 42 (Figure 3). In weeks 32 and 33, actually more than $73 \%$ of all cows were present in sector A during the Period 2 . An overall maximum was reached at 13.30 in week 32; on the day of measuring, $89.01 \%$ of all cows were present in sector A (about 90 cows were crowded on an area of mere $209 \mathrm{~m}^{2}$ ). There was no significant correlation between the average ambient air temperature in the barn and the percentage of dairy cows present in sector $A$ in Period $2(r=0.47, P=0.09)$.

At the beginning of this study (week 27 ) only about $8 \%$ of dairy cows were observed standing during Period 2 (Figure 4). The proportion of cows standing in Period 2 thereafter gradually increased and reached its maximum of nearly $44 \%$ in week 32 . It was observed that most of the cows that were standing in the crowded area oriented their heads to the back of other cows in the group. There was a highly significant correlation between crowding (\% of cows in sector $A$ ) and numbers of standing cows $(r=0.97, P<0.001)$. However, increased crowding did not affect the time spent for eating $(r=0.44, P>0.10)$. A percentage of dairy cows standing in the cubicle dropped from $17.48 \%$ in week 27 to $4.68 \%$ in week 33 and started to increase again towards the end of crowding period. However, this was caused, above all, by an increase in numbers of cows present in sector $A$. The crowding behaviour of dairy cows had a similar effect on the time spent for lying. 


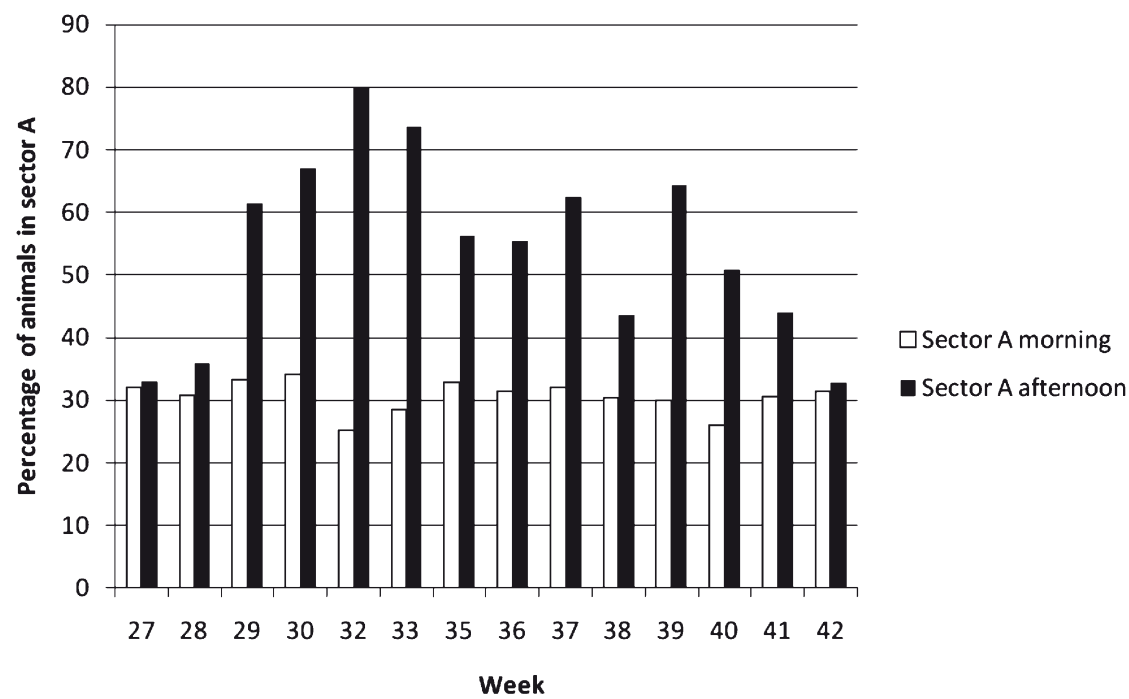

Figure 3

Percentages of cows present in sector A in Periods 1 (morning) and 2 (afternoon)

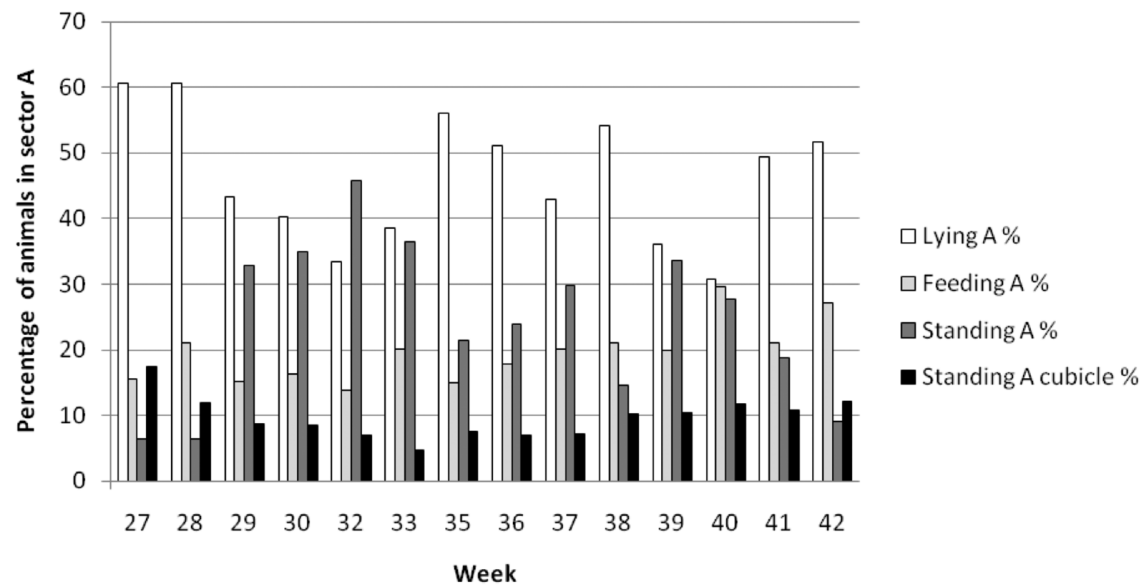

Figure 4

Percentage of cows lying, feeding, standing and standing in cubicles in sector A

\section{Discussion}

Results of this study confirmed observations of farmers that in cubicle housing systems, dairy cows crowded together on warm summer days. Interestingly, the crowding was observed only during Period 2 and not in Period 1 . The air temperature inside the barn was naturally higher in Period 2 than in Period 1 and the afternoon values of the THI-index were higher than 70 for all observation days until week 38 . According to some authors, these THI values are stressful and could affect heat stress for cows in lactation (e.g. Kadzere et al. 2002). It was rather strange that animals exposed to the heat stress showed the crowding behaviour, as observed in this study. When crowding, the heat load of animals further increases, and 
it is quite clear that for heat-stressed animals crowding is very disadvantageous. Studies performed with pigs showed that animals actually reduced their negative heat stress by lying closer to each other and that they reduced huddling (Boon 1981, Ekkel et al. 2003, Vasdal et al. 2009). Simultaneously with the crowding, the time dairy cows spent standing increased as well. When a high number of animals were gathered in sector $A$, the access to cubicles was rather limited but the more frequent standing position was also a strategy for how to reduce the discomfort which came from the heat stress (Tapkı \& Şahin 2006, Cook et al. 2007). Shortened periods of lying may negatively affect performance of dairy cows, as few studies demonstrated that a reduced lying time impaired the milk yield (Metcalf et al. 1992, Rulquin \& Caudal 1992). In our experiment, crowding actually did not affect the time spent for eating. As the feed was evenly distributed along the feed barrier, we excluded it as a potential cause of crowding. Moreover, feeds in parts where cows did not crowd, during crowding time, were almost »untouched«. However, Erbez et al. (2010b) observed a more intense competition for position in stall during the crowding period, where group of cows tending to stand in feeding alley produced more milk, then those in the group standing in dung channel.

Why those cows preferred to clump together in sector $A$ and not in sectors $B$ or $C$, is a question difficult to answer and explain. Also, cows in the other sections of the barn crowded in the sector nearest to the centre of the barn. One of the factors that may explain this crowding phenomenon is a reduction of irritation from insects. It seems reasonable to suggest that by crowding the animals reduce the body surface area that is exposed to insects. Most of the cows that were standing in the crowded area oriented their heads to the back of other cows, possibly because they aimed to protect the head zone (eyes and nostrils) as very vulnerable parts of a cow's body. Since the animals in the present study were willing to increase the heat load further although they were already under heat stress, the irritation of the insects must be considerable as a crowding trigger. Correspondingly, King \& Gurnell (2010) observed that during the warmer hours of the day in warm months Przewalski horses moved up to higher, bare places with lack of pasture, most likely to escape from flies. This could be explained by the fact that horses chose to eat less than to be irritated by flies.

However, since the problem of irritation by insects was not a subject of our research study, this possibility stands as just one possible explanation.

\section{Acknowledgements}

This study was supported by the Research Project $n^{\circ}$ MSM6215648905 »Biological and technological aspects of sustainability of controlled ecosystems and their adaptability to climate change«, which is financed by the Ministry of Education, Youth and Sports of the Czech Republic and Internal grant of Mendel University IG TP 01/2012. We also wish to express our thanks to the Department of International Environment and Development Studies, NORAGRIC - Norwegian University of Life Science, Ås, Norway for their support

\section{References}

Andersen IL, Bøe KE, Hove K (2000) Behavioural and physiological thermoregulation in groups of pregnant sows housed in a kennel system at low temperatures. Can J Anim Sci 80, 1-8

Bøe KE (1990) Thermoregulatory behaviour of sheep housed in insulated and uninsulated buildings. Appl Anim Behav Sci 27, 243-252 
Boon CR (1981) The effect of departures from lower critical temperature on the group postural behaviour of pigs. Anim Prod 33, 71-79

Cook NB, Mentink RL, Bennett TB, Burgi K (2007) The Effect of Heat Stress and Lameness on Time Budgets of Lactating Dairy Cows. J Dairy Sci 90, 1674-1682

Ekkel ED, Spoolder HAM, Hulsegge I, Hopster H (2003) Lying characteristics as determinants for space requirements in pigs. Appl Anim Behav Sci 80, 19-30

Erbez M, Falta D, Chládek G (2010a) Categorization of crowding behaviour in dairy cows during summer period. In: MendelNet, Mendel University in Brno, 247-252

Erbez M, Bøe KE, Falta D, Chládek G (2010b) Effect of self-willed crowding period on stall position and performance in Czech Fleckvieh Cattle. Animal welfare, ethology and housing systems 2, 118-123

Friend TH, Gwazdauskas FC, Polan CE (1979) Change in adrenal response from free stall competition. J Dairy Sci 62, 768-771

Hanuš O, Kučera J, Yong T, Chládek G, Holásek R, Třináctý J, Genčurová V, Sojková K (2011) Effect of sires on wide scale of milk indicators in first calving Czech Fleckvieh cows. Arch Tierz 54, 36-50

Hill CT, Krawczel PD, Dann HM, Ballard CS, Hovey RC, Falls WA, Grant RJ (2009) Effect of stocking density on the short-term behavioural responses of dairy cows. Appl Anim Behav Sci 117, 144-149

Hurnik JF, Webster AB, Siegel PB (eds., 1995) Dictionary of Farm Animal Behaviour, 2nd ed. lowa State University Press, Ames, IA, USA

Huzzey JM, DeVries TJ, Valois P, von Keyserlingk MAG (2006) Stocking density and feed barrier design affect the feeding and social behaviour of dairy cattle. J Dairy Sci 89, 126-133

Kadzere CT, Murphy MR, Silanikove N, Maltz E (2002) Heat stress in lactating dairy cows: a review. Livest Prod Sci 77, 59-91

King SRB, Gurnell J (2010) Effects of fly disturbance on the behaviour of a population of reintroduced Przewalski horses (Equus ferus przewalskii) in Mongolia. Appl Anim Behav Sci 125, $22-29$

Metcalf JA, Roberts SJ, Sutton JD (1992) Variations in blood flow to and from the bovine mammary gland measured using transit time ultrasound and dye dilution. Res Vet Sci 53, 59-63

Rulquin H, Caudal JP (1992) Effects of lying or standing on mammary blood flow and heart rate of dairy cows. Ann Zootech 41, 101

Tapkı I, Şahin A (2006) Comparison of the thermoregulatory behaviours of low and high producing dairy cows in a hot environment. Appl Anim Behav Sci 99, 1-11

Vasdal G, Wheeler EF, Bøe KE (2009) Effect of infrared temperature on thermoregulatory behavior in suckling piglets. Animal 3, 1449-1454

Received 29 July 2011, accepted 12 April 2012.

Corresponding author:

Miljan Erbez

email:miljanerbez@gmail.com

Ministry of Agriculture, Forestry and Water Management of Republic of Srpska, Trg Republike Srpske 1, 78000 Banja Luka, Bosnia and Herzegovina 